\title{
An Analysis Of The Differences Between Student Age And Social Networking Utilization Within A School Of Business
}

Ken Zula, Ph.D., SPHR - Keystone College, USA

Karen K. Yarrish, Ph.D., SPHR - Keystone College, USA

Walter Pawelzik - Keystone College, USA

\begin{abstract}
Social networking sites such as Facebook, LinkedIn, and Twitter are widely regarded as an exciting opportunity to communicate with friends, especially for college students. The overall response to social networking tends to be one of trust regarding a generation that, supposedly has many friends but little sense of privacy. Employers use social media sites to perform preliminary screenings of potential employees. The information students post on social media sites can be used in making employment decisions. This article examines the difference between student age, and career exploration/research and social networking usage. The researchers will discuss the implications for educators, administrators, and researchers. Findings, conclusions, and recommendations will be presented.
\end{abstract}

Keywords: Social Networking; Career Exploration; College Students

\section{INTRODUCTION}

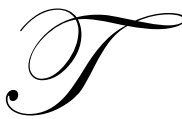

he use of social media has become an important part of daily activity for most college students. According to Budden, Anthony, Budden, and Jones (2007), students were found to spend large amounts of time using a variety of media. The utilization of these social media sites such as Facebook, LinkedIn, and Twitter, could be changing the way students approach future employment. A recent study showed that students were nearly split in reporting whether or not they believed employers had access and were viewing their social networking profile (Vicknair, Elkersh, Yancey, \& Budden, 2010).

The total users in 2009 for Facebook and LinkedIn were reported at over 200 million and 39 million respectively (Davis, Bailey, Day-Burget, Sinclair, \& Shah, 2009). The use of each of these social sites is mildly different in that Facebook was initially designed for personal networking whereas LinkedIn is geared toward a more professional/career based audience (Davis, Bailey, Day-Burget, Sinclair, \& Shah, 2009). While research in the practitioner literature suggest that networking behaviors, such as socializing by going out for drinks and discussing business issues informally, attending conferences, are essential to career success current research is still attempting to determine the role social media plays, if any, in career success (Nierenberg, 2002; Torres, 2005).

Internet based hiring and job postings are thoroughly presented online by the industry leader monster.com, but even as a leader in the field monster.com maintains six Twitter accounts, three Facebook accounts, and five other internet media site accounts including Friendfeed and YouTube (Social Media, 2011). This leads to the question, what does the future hold for internet based hiring practices with college students?

The market of social media is ever expanding with more than 100 different social media sites on the internet today (Lewis, 2010). Students have the ability to access and utilize any of these for whatever they see fit. The popularity of these websites has also introduced the ability for anyone, anywhere to build and create their own social network based on their own wants and needs (Lewis, 2010). Different studies on the topic of social media 
sites show that there are an overwhelmingly large number of users on them and with that introduce just as many different reasons for utilizing these sites (Lewis, 2010). Decker (2006) believes that students have a sense of privacy when participating in online social networks. Privacy advocates are pushing for regulation or at least standards that would apply to social networking to provide clear safeguards for social network users in regard to the transfer of personal data (MacMillan, 2009). While both women and men have about the same number of social network friends, Hoy and Milne (2010) found that women find it more important to know how their personal information is posted and used.

The different reasons for utilizing social media from a user perspective is now emerging in the human resource management segments of firms looking to hire new employees (Budden \& Budden, 2009). Through the use of social media sites firms can now perform preliminary screenings of potential employees and look into the activities of current employees (Budden \& Budden, 2009). The benefits of this method can provide useful information for the firm as a source of proficient and intelligent potential employee's along with a way to gauge the character of the employee. The benefits however hold just as much value for the user. There is potential for the ability to search for information about the company and interact with current employees on the company's social media website account (Budden \& Budden, 2009).

Websites such as www.about-monster.com have their social media website accounts focused at all possible users of their website. The twitter accounts alone are set up to be an area for interaction for job seekers and employers as well as monster news updates, philanthropy, recruiters and customer service (Social Media, 2011). Employers have rescinded job offers to students based on information pulled from social networking sites that show the student in comprising and unprofessional situations (Pelluchette \& Karl, 2008).

\section{PURPOSE}

The purpose of this study is to determine the utilization of social networking between student age and social networking utilization and career exploration/research, within a school of business. According to Harrison (2008), students are unaware of employers utilizing social networking websites such as Facebook to verify and conduct unofficial background checks on potential candidates for vacant positions. In addition, Decker (2006) states that students are hurting their future employment options by engaging in a relaxed attitude towards personal privacy by posting inappropriate comments, photos, and other material.

\section{WHAT IS SOCIAL NETWORKING?}

Boyd and Ellison (2008) define social network sites as web-based services that allow individuals to construct a public or semi-public profile within a bounded system, articulate a list of other users with whom they share a connection, and view and traverse their list of connections and those made by others within the system. The nature and nomenclature of these connections may vary from site to site (para. 4).

\section{RESEARCH QUESTIONS AND VARIABLES}

RQ 1: What is the correlation between student age and time spent utilizing social networking websites?

RQ 2: What is the correlation between student age and social networking website utilization for career exploration/research?

\section{PARTICIPANTS}

The participants (Table 1) in this study were college aged students $(18-20-n=50,47 \%)$ and $(21-24+-n$ $=55$ or 53\%) enrolled in a small liberal arts college with a declared major in business or business administration. Students were enrolled in both two-year (Associate Degree) and four-year (Bachelor Degree) programs. There were one hundred five participants in this study $(n=105)$. In addition, students were categorically classified as male and female, as well as freshman, sophomore, junior, or senior students. It should be noted that all students were traditional students. There were no distance education or adult (non-traditional) students included in this study. 


\section{INSTRUMENT}

The instrument used to measure student utilization of social networking websites was a self-designed, first generation instrument consisting of 21 items within two dimensions - Career Exploration/Research, and Time Spent. These dimensions measured the student's utilization and perceptions of social networking websites for career exploration, group and friend interaction, posting content, and time spent. The instrument is divided into two dimensions - time spent and career research. Internal reliability of the scale, the internal consistency is . 76 for the career dimensions and supporting items $(\alpha=.76)$ and with the subscales between $.71-.88$ (Nunnally, 1970).

\section{PROCEDURE}

Independent $\mathrm{t}$ tests were utilized to examine whether age impacted the utilization of social networking websites for career exploration and to determine if there was a significant difference of time spent on social network websites depending on age within a small liberal arts college school of business. There was no significant difference found between age and time spent on social networking websites, however there was a significant difference between age and career exploration/research on social networking websites. Statistical analysis was carried out using SPSS for Windows (19.0).

\section{FINDINGS}

The results of this study indicate that there is a significant difference between age and career exploration/research, however there was no significance between age and social networking websites utilization at a small liberal arts college in Northeastern Pennsylvania. The results will be reported separately within the two dimensions established within the survey. Participants answered questions regarding Career Exploration and Time Spent.

Results for Career Exploration are reported as follows (Table 2). There was a significant difference between age and the Career Research item. The independent $t$ test results reveal that aged 21-24+ participants $(M$ $=1.26, S E=.06)$ rated career research as more important than participants aged 18-20. This difference was significant $t(.408)=.041, \mathrm{p}<.05$. There was a medium sized effect $r=-.426$. There was no significant difference between age and the Employment Opportunity dimension. The $t$ test results reveal no significance (.620) $=.62, \mathrm{p}$ $<.05$. Although, there was a small effect size $r=.315$. There was a significant difference between age and the Refer Employers item. The independent $t$ test results reveal that aged 21-24+ participants $(M=1.68, S E=.06)$ rated refer employers as more important than participants aged 18-20. This difference was significant $t(.039)=.039$, $\mathrm{p}<.05$. There was a medium effect size $r=.479$. There was a significant difference between age and the Application item. The independent $t$ test results reveal that aged 21-24+ participants $(M=1.18, S E=.06)$ rated application as more important than participants aged 18-20. This difference was significant $t(.010)=.010, \mathrm{p}<.05$. There was a small effect size $r=.108$. There was a significant difference between age and the Recruitment item. The independent $\mathrm{t}$ test results reveal that aged 21-24+ participants $(M=1.36, S E=.07)$ rated recruitment as more important than participants aged 18-20. This difference was significant $t(.0384)=.038, \mathrm{p}<.05$. There was no significant difference between age and the Public Life item. The $t$ test results reveal no significance $(.874)=.87, \mathrm{p}<$ .05 . Although, there was a small effect size $r=.106$. There was not a significant difference between age and the Fairness item. The $t$ test results reveal no significance $(.902)=.90, \mathrm{p}<.05$. Although, there was a small effect size $r$ $=.013$. There was a significant difference between age and the Potential Employment item. The independent $t$ test results reveal that aged 21-24+ participants $(M=1.72, S E=.06)$ rated potential employment as more important than participants aged 18-20. This difference was significant $t(.0014)=.001, \mathrm{p}<.05$.

Results for Time Spent are reported as follows (Table 2). There was no significance amongst the items measuring usage of social networking websites, reading updates on social networking websites, and posting updates on social networking websites. Although, the results for multiple accounts was not significant, it is interesting to note that 5 participants held multiple accounts in order to hide information from parents/family $(\mathrm{n}=2)$, hide information from potential employers $(n=1)$, and three participants indicated another rationale. 
Table 1

Student Classifications/Demographics

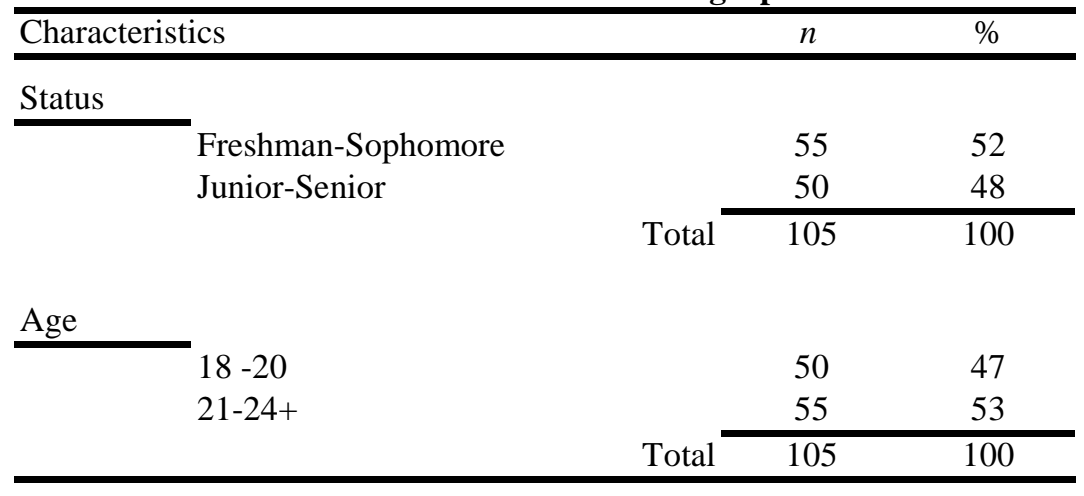

Table 2

Independent $t$ test results for time spent and career exploration within social networking

\begin{tabular}{lllll}
\hline Social Networking Dimensions & $F$ & $d f$ & $t$ & Significance \\
\hline $\begin{array}{l}\text { Career Exploration } \\
\text { Career Research }\end{array}$ & 0.671 & 95 & 0.408 & $* .041$ \\
$\quad$ Employment & & & & \\
Opportunity & 0.248 & 88 & 0.248 & .062 \\
Refer Employers & 0.724 & 95 & 0.429 & $* .039$ \\
Application & 0.269 & 95 & 0.836 & $* .010$ \\
Recruitment & 0.760 & 95 & 0.444 & $* .038$ \\
Public Life & 0.024 & 95 & 0.024 & .087 \\
Fairness & 0.015 & 95 & 0.291 & .090 \\
Potential Employment & 0.215 & 95 & 0.215 & $* .001$ \\
$\quad$ & & & & \\
Time Spent & & & & .090 \\
Usage & 0.016 & 95 & 0.016 & .080 \\
Multiple Accounts & 0.258 & 95 & 0.226 & .063 \\
Reading Updates & 0.227 & 95 & 0.228 & .072 \\
Posting Updates & 0.124 & 95 & 0.534 &
\end{tabular}

$* \mathrm{p}<.05$

Note: Career exploration dimension contains 8 items soliciting input for career research/exploration. Usage dimension contains 4 items soliciting input for time spent on social networking activities.

The results of this study reveal that there are significant differences for age and career exploration/research and no significant difference between age and time spent on social networking websites. In particular, younger participants (18-20 yrs of age) in this study rated career exploration/research as less important than the older participants (21-24+ yrs of age) in this research.

\section{IMPLICATIONS}

There are significant differences in the career exploration dimensions of career research, refer employers, application, recruitment, and potential employment between the $18-20$ and $21-24+$ aged participants in this study. The results of the study have implications for career counselors, employment coaches, human resource professionals 
and individuals with social networking accounts including college students. College counselors and employment coaches should take these results into account when developing and delivering career seminars, and providing advice to college students, and those seeking future employment, those changing employment, and/or those reentering the workforce. Human resource professionals should consider these findings when utilizing social networking websites to verify and conduct background investigations with potential employees, and current employees.

College students must be aware that their social networking profiles which are public or semi-public (Boyd \& Ellison, 2008) and include a list of users (friends), as well as a description and permanent record of the interaction with other users and posted photographs, video, and written statements are being accessed by potential employers to verify viability for employment. Students have developed a sense of trust and a little sense of privacy regarding their life; these may have implications for future employment. This study indicated that students begin to evolve and utilize social networking websites for prospective career opportunities in their later college years. In addition, students begin to gain a comfort level with referring potential employers to their social network profiles. As a result, there is a potential to limit employment opportunities based upon the content of these social network profiles.

\section{LIMITATIONS}

Research conducted with students as the primary sample is a limitation of this study. It is important to study a diverse population; the sample of this study was limited to students attending a private liberal arts college in Northeast Pennsylvania. The sample of this study should be expanded to include additional student populations such as distance education and non-traditional or adult students from this college and other colleges and universities throughout the United States. In addition, the sample could be expanded to include recent graduates within the workforce in order to create a more diverse study sample. A further enhancement to this study would include a global population of students to gain student perspectives on leadership skills from around the globe.

\section{RECOMMENDATIONS}

Students, and others utilizing social networking profiles must be cognizant of the potential verification and perusal by prospective employers. According to Pelluchette and Karl (2008), employers have rescinded job offers to students based upon information pulled from social networking websites that show the student in comprising and unprofessional situations. Social networking profiles have grown in popularity amongst all generations. Users of these websites must be aware of the possible consequences of gaining employment based upon the content of a public or semi-public profile. Students, in particular, must be educated about the appropriateness of content on these websites since they can be powerful tools for gainful employment.

Finally, future research would benefit from expansion of this study beyond students. Any expansion beyond the current population utilized for this study will provide a greater opportunity to continue to develop this study. In particular, the study can be expanded to the currently unemployed in order to gain knowledge about their use and consideration of social networking profiles in their attempt to re-enter the workforce. This study only began to delve below the surface of social networking. There are numerous opportunities for researchers to continue to build upon this study to determine the powerful use of these types of websites.

\section{AUTHOR INFORMATION}

Ken Zula, Ph.D., SPHR is Assistant Professor of Business and Chairperson of the Department of Business, Management, and Technology at Keystone College. He received his Ph.D. in Human Resource Development from the Pennsylvania State University and is a certified Senior Professional in Human Resources (SPHR). He held the professional position of Vice-President of Human Resources prior to entering academia. He can be reached at ken.zula@keystone.edu.

Karen Yarrish, Ph.D., SPHR is an Associate Professor of Business at Keystone College. She received her Ph.D. in Human Resource Development from the Pennsylvania State University and is a certified Senior Professional in Human Resources (SPHR). She held the professional position of Director of Human Resources at King's College and SallieMae prior to moving into academia. She can be reached at karen.yarrish@keystone.edu. 
Walter Pawelzik is a senior at Keystone College. He is pursuing a bachelor's degree in business administration with a minor in accounting and finance. He will be pursuing a graduate degree in the future. He can be reached at walter.pawelzik@keystone.edu.

\section{REFERENCES}

1. Boyd, D. M. \& Ellison, N. B. (2008). Social network sites: Definition, history, and scholarship. Journal of Computer-Mediated Communication. 13(1), 210-230.

2. Budden, C.B., Anthony, J.F., Budden, M.C., \& Jones, M.A. (2007). Managing the evolution of a revolution: Marketing implications of internet media usage among college students. College Teaching Methods \& Styles Journal, 3(3), Retrieved February 4, 2011, from http://www.cluteinstituteonlinejournals.com/PDFs/450.pdf

3. Budden, C, \& Budden, M. (2009). The social network generation and implications for human resource managers. Journal of Business \& Economics Research, 7(1), Retrieved February 4, 2011, from http://www.cluteinstitute-onlinejournals.com/PDFs/976.pdf

4. Davis, C., Bailey, S., Day-Burget, J., Sinclair, A., \& Shah, A. (2009). Building and recruiting qualified candidates for water industry jobs. Journal AWWA, 101(8). Retrieved February 14, 2011 from http://www.awwa.org/files/Resources/WorkForWater/JAW200908well03davis.pdf

5. Decker, J. (2006). Online Self reported information: Facebook a hiring tool for business. Thesis. Iowa State University, 2006. Ann Arbor: Proquest Information and Learning Company, 2007.

6. Harrison, J. L., (2008). Employer and recruiter use of social networking websites screening tool. Thesis. Gonzaga University, 2008, Spokane: Proquest Information and Learning Company, 2008.

7. Hoy, M. G. \& Milne, G. (2010). Gender differences in privacy-related measures for young adult facebook users. Journal of Interactive Advertising, 10(2), 28-45.

8. Lewis, B. (2010). Social media and strategic communication: attitudes and perceptions among college students. Public Relations Journal, 4(3), Retrieved February 4, 2011 from http://www.prsa.org/Intelligence/PRJournal/Documents/social_media_and_strategic communication.pdf

9. MacMillian, D. (2009). Facebook connect: Your 8,000 hidden friends. Bloomberg Businessweek, April, 2, 2009.

10. Nierenberg, A. R. (2002). Nonstop networking. Hendon, VA: Capital Books.

11. Nunnaly, J.C. (1970). Introduction to psychological measure (2nd ed.). New York: McGraw-Hill.

12. Pelluchette, J. \& Karl, K. (2008). Social networking profiles: An examination of student attitudes regarding use and appropriateness of content. CyberPsychology \& Behavior, 11(1), 95-97.

13. Social Media. Monster.com. (2011). Retrieved February 14, 2011, from monster.com.

14. Torres, N. L. (2005). It's who you know. Entrepreneur, 33, 128-132.

15. Vicknair, J., Elkersh, D., Yancey, K., \& Budden. M. (2010). The Use of social networking websites as a recruiting tool for employers. American Journal of Business Education 3(11), 07-12. 